\title{
Fuzzy Sliding Mode Control of a Ball Screw Driven Stage
}

\author{
Mohammad Shams ${ }^{1}$ and Masoud Safdari ${ }^{2}$ \\ ${ }^{1}$ MSc. In Manufacturing, \\ ${ }_{2}^{2}$ hD Student, Mechanical Engineering Dept, University of New Mexico \\ ${ }^{1}$ Iran, \\ $2 U S A$
}

\section{Introduction}

Nowadays by introduction of Nanotechnology as cutting edge of research, researchers are studying and investigating phenomenon in nanoscales. Almost all various tools required for this purpose are calling for next generation of positioning systems with far better precision than available counterparts. As instance processes such as ultra precision machining and micro assembly require high precision positioning systems. These processes have their applications in semiconductor, optical and precision metrology industries. Accordingly there are vast varieties of available positioning systems. Among them, fines pitch screws, differential screws, piezo electric positioning systems, linear motors and ball screw driven stages could be mentioned. Each system has its own advantages and disadvantages. For example generally speaking a piezoelectric positioning system has better positioning accuracy while the stroke, the velocity and the maximum thrust force of this system is more limited. Ball screw driven systems have been the subject of much attention because of their major advantages like large stroke, higher speeds and thrust force, availability and low cost. Despite the architecture of each system, in order to achieve high precision in positioning, it is important to resolve the performance characteristics of the system in micro and submicron scale. Nonlinear phenomena such as friction, backlash and compliance can reduce the positioning precision and tracking accuracy. Among them friction always plays a key role.

The nonlinear behavior of friction may lead to consequences like limit cycle and instability in the dynamic system. As a consequence such behavior in a control system demands for more complex hierarchy in its controller. In other words, nonlinear positioning systems are mostly less precise in positioning and less accurate in tracking. Two important consequences of friction in sliding systems are steady state error in positioning in positioning and lag in tracking. These two are direct effect of the Stick-Slip behavior of friction. To eliminate these deficiencies, the nonlinear effects of friction should be compensated. Therefore a behavioral model of friction is required to eliminate these effects.

Various researches have been carried out to characterize and model the friction in a positioning system. Dahl et al. proposed a dynamic model describing the spring like behavior during stiction (Dahl, 1968). One shortcomings of this model is that Stribeck effect had not been considered in this model. First attempt to incorporate Stribeck effect to Dahl model has been done by Bliman and Sorine (Bliman \& Sorine, 1991). Canudas et al. 
proposed a model that captures most of frictional behaviors such as hysteresis, spring - like behavior during stiction, Stribeck effect and variable break - away force observed in practice (Canudas et al., 1995).

In order to compensate the friction in a controlled positioning system, different types of controllers have been proposed. Ro et al. developed a PD control scheme with a nonlinear friction estimation algorithm based on Canudas friction model for submicrometer positioning and tracking (Ro et al., 2000). In addition, variable structure systems can also be employed to compensate consequences of friction in motion. For instance sliding mode control can be utilized. This type of controller can treat a variety of uncertainties as well as bounded external disturbances and satisfy system characteristics such as stability, elimination or decrease of chattering, linearization of nonlinear and order reduction in accordance with a design target. However sliding mode controllers suffer from chatter phenomena. In order to reduce the chattering, especially in the systems with some degrees of uncertainty, more sophisticated controlling schemes like boundary layer sliding mode controller and integral sliding mode control are proposed. These controlling schemes can compromise between small chattering and good tracking precision. Chen et al. compensated for friction in static and dynamic regimes in a ball screw driven stage by developing a sliding mode controller for each regime (Chen et al. 2004). Fuzzy logic controllers are another type of variable structure controllers which are more applicable to complex systems and ill-defined systems. Regarding the fact that the governing parameters of friction model are mostly hard to define and also these parameters are subject to change in various controlling environments, it is suitable to utilize variable structure controllers for the purpose of compensation.

Fuzzy sliding mode control is another control strategy that attracts a great deal of interest. Lee et al. developed a sliding mode controller based on fuzzy variable boundary layer with a control gain and boundary layer thickness as design parameters (Lee et al., 2001). Liang et al. proposed a two input single output (TISO) fuzzy sliding mode controller (FSMC) by developing complementary sliding mode controller (CSMC) (Liang \&, 2003). Mihajlov et al. applied a sliding mode controller enhanced by fuzzy PI controller to an electro-hydraulic positioning system, whose model includes internal friction (Mihajlov1 et al., 2002).

In following chapter, the phenomena of backlash and friction are introduced firstly and then Canudas friction model (Canudas et al., 1995) is used to capture the frictional behaviors in a ball screw driven stage. Conventional sliding mode control with boundary layer, complementary sliding mode control and TISO fuzzy sliding mode control (Liang \&, 2003) are applied to this dynamic system for the purpose of the compensation of friction effects. Finally the performances of various controllers are evaluated in the sense of submicrometer positioning, tracking accuracy and control input to the system.

The outline of this chapter is as follows. In section 2, backlash and friction are described and then friction model proposed by Canudas is briefly introduced. In section 3, model of dynamic system is explained. In section 4, theory of sliding mode control is explained at first and then CSMC and TISO FSMC are described. Sections 5 and 6 include designed parameters and computer simulation respectively. The chapter ends with conclusion and future work remarks in section 7.

\section{Introducing system nonlinearities}

Friction and backlash are two important nonlinearities which dominate performances of ball screw driven stages in the sense of positioning precision and tracking accuracy. The term 
friction indicates any speed or force-dependent energy dissipation in a machine. Backlash implies mechanical hysteresis and multibody impaction. An introduction to these topics is outlined below and then a model for friction is introduced.

\subsection{Backlash}

In conventional engineering terminology, backlash is the distance through which one part of connected machinery, as a gear, or screw, can be moved without moving the connected parts, resulting from looseness in fitting or from wear. In other word, backlash results in mechanical hysteresis. Basically the existence of backlash between the components of a machine like ball screw and gears reduces machine's accuracy. Two main features of backlash are mechanical hysteresis and the impact which is mostly important between two relatively hard surfaces in contact. In classic model backlash is considered as an unsymmetrical deadband around the equilibrium. In this model for the simplicity it is assumed that all of dynamic impacts are fully plastic and therefore exhausting in the backlash zone. Figure 1 illustrates the phenomenon of backlash, reaction versus action, based on classical modeling considerations. It is worth noting that the slope and the deadbands may differ in either side.

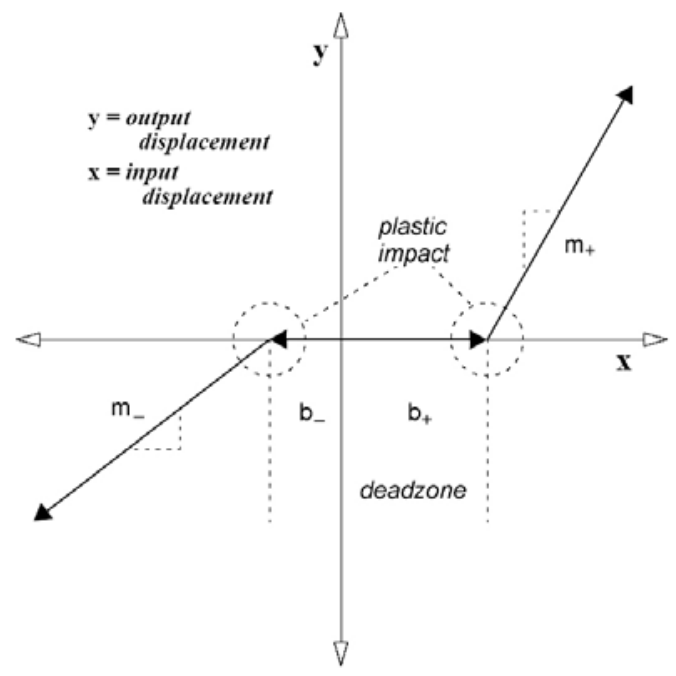

Fig. 1. Classical model of backlash. (de Marchi. 1998)

In modern model, both features of backlash which are mostly effective on the accuracy of the positioning in machine tool have been considered. In this model, the backlash is considered as a combination of deadband and an almost elastic impact between numbers of rigid bodies in contact. The impact can cause transient vibrations between rigid bodies (e.g. components made of hard metal). The existence of low frequency vibrations causes inaccuracy in positioning. The deadband in this model indicates the region in which there is not any considerable motion in output for a motion in input. In analogy with friction the deadband is similar to hysteresis caused by pre-sliding friction. The deadband is covering the point in which the velocity reduced to zero (the point of change in direction). Figure 2 illustrates the modern backlash model. 


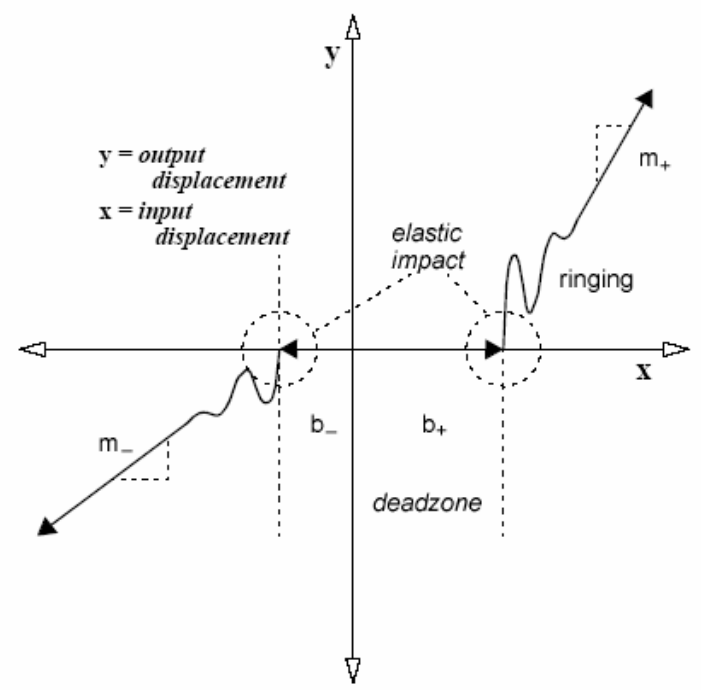

Fig. 2. Modern model of backlash. (de Marchi. 1998)

\subsection{Friction}

Friction force initiates from relative motion during contact and resists this motion. There are at least two different physical explanations for friction.

\subsubsection{Classical friction model (static, dynamic and viscous)}

Based on this model the mechanical clamping between surface asperities during contact is the origin of friction in case of static and dynamic friction. Thus the there should be a direct relation between the contact load (in vertical direction) and the friction force. However either the shape of contact surfaces or its effective contact area does not contribute to the friction. Additionally based on this model static friction force should be greater than dynamic friction force. Based on experimental results the coefficient of friction has been measured. It is also confirmed that the friction force is directly dependent to contact load. This model has been constructed based on the following assumptions:

- In each case, bulk and surface properties of the contacting pairs contribute to the friction.

- The amount of static friction force depends on the duration of contact.

- The amount of dynamic friction force is independent from sliding velocity of contact.

- A fraction of friction force is also dependent on the magnitude of adhesion force between the molecules on the contact surfaces.

Based on empirical investigations, the principle of Columb's friction represents friction as a simple mathematic relation:

$$
f=n+t
$$

Which $\mathrm{f}$ is the contact force, $\mathrm{n}$ is the normal force and $t<\mu n$ is the tangential shear force carried out by two surfaces in opposite direction of motion. 
During sliding, $\mathrm{t}=\mu_{\mathrm{k}} \mathrm{n}$ and in its threshold $t=\mu_{\mathrm{s}} n$. Typically $\mu_{\mathrm{s}}=\mu_{\mathrm{k}}$ and the $\mu_{\mathrm{s}}$ and $\mu_{k}$ are called the coefficients of static and dynamic friction respectively. The magnitude of $\mu_{s}$ and $\mu_{k}$ are taken to be constant for each pair of rubbing materials. The Columb's friction model investigated above provides a close approximation for clean, dry and geometrically regular surfaces in contact. The Columb's law of dynamic friction claims:

- The friction force is proportional to the contact load. Contact load is the magnitude of force acting along normal direction to the contact surfaces.

- For a constant load, the friction force is independent of the area of contact.

- The friction is independent of sliding velocity.

- The friction force is dependent to the nature of the pair of materials in contact.

During industrial revolution and introduction of high speed machines, a speed-dependent component of friction became evident, called viscous friction. Reynolds was the first person who investigated this type of friction which was related to the viscosity of a lubricant. The lubricants are typically non-Newtonian type and their viscosity increase with increasing shearing velocity. Figure 3 illustrates the friction model integrating static, dynamic and viscous types of friction.

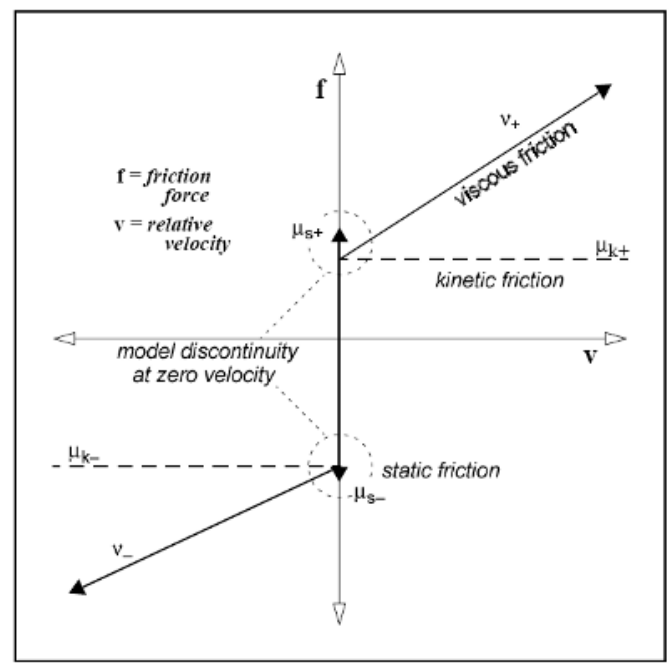

Fig. 3. Classical model of friction (static, dynamic and viscous). (de Marchi. 1998)

\subsubsection{Modern model of friction (rolling friction, stribeck, stick-slip, hydraulic)}

Contrasting classic model, modern model is more explicable via contact adhesion theories. Several reasons can be mentioned for this e.g. despite common sense; very smooth surfaces provide more friction than rougher surfaces. Researchers observed that actual area of contact is much less than apparent area. This difference that is due to surface asperities and the area of actual contact can be measured easily by measuring electrical conductivity between two surfaces in contact. In this model it is assumed that the magnitude of friction force is proportional to actual area of contact which is a fraction of apparent area. Since the actual area of contact is small, small amount of contact load causes enough pressure to weld contacting points to each other. So based on this model, frictional resistance is primarily 
attributed to shearing of welds in contact points and secondarily to the stage of plowing the softer material by the harder one.

Based on experimental data gathered by Stribeck, the transition process from static friction stage to dynamic friction stage and finally to viscous stage is continuous. During measurement of friction on a spindle, he noted that the friction rapidly changes from its static value to a minimum dynamic value and then it will approach to its linear viscous friction. This transition that is a velocity dependent phenomenon is called Stribeck effect. This phenomenon is only observable over a very small velocity range and almost standstill or varies over a very long period of time during steady state operation. Stribeck friction sometimes is called negative friction which is because of existence of negative slope in the friction versus velocity curve. Later other researchers stated that negative friction is the prerequisite of the Stick-Slip phenomenon. This phenomenon originates from switching from static friction scheme to dynamic friction scheme between contacting surfaces. Finally disagreement on the dependence of friction force on velocity has been resolved as following:

- At very low speeds, friction force increases as speed increases.

- At medium speeds, $(25 \mathrm{~mm} / \mathrm{s} \sim 30 \mathrm{~cm} / \mathrm{s})$, friction force is almost independent of speed.

- At high speeds, friction force decreases as speed increases.

In very high speeds, it is accepted that the friction force decreases because of the separation of contact surfaces and therefore the molecular attraction and adhesion forces decreases. The modern friction model is illustrated in Fig 4 (de Marchi. 1998).

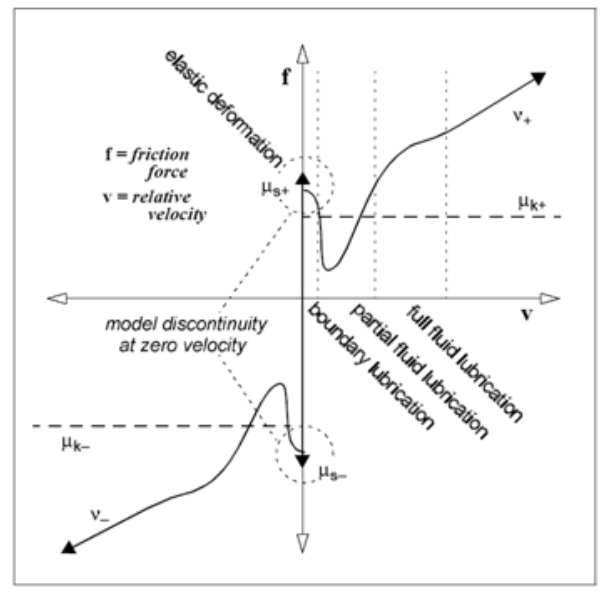

Fig. 4. Modern model of friction (static, Stribeck and viscous). (de Marchi. 1998)

\subsection{Friction model}

In order to achieve the desired precision in positioning and tracking, friction should be compensated. Therefore a frictional model capable to describe various behaviors of this nonlinear phenomenon should be used. Canudas (Canudas et al., 1995) proposed a model that considers the friction interface as elastic bristles which are attached to rigid solids (Fig.5). Relative velocity between the surfaces causes the bristles to be deformed and this deformation can be regarded as the source of friction. The governing equation of average bristle deflection can be stated as 


$$
\frac{d z}{d t}=v-\frac{|v|}{g(v)} z
$$

where $v$ is the relative velocity between two surfaces. The function $g(v)$ is positive and depends on factors such as material properties, lubrication and temperature and is inevitable not symmetrical. This function has direction dependent behavior. The correspondence of $g(v)$ to Stribeck effect is verified by the fact that $g(v)$ decreased monotonically by increasing speed. The friction force (torque) generated from bending of bristles and viscous friction can be stated as

$$
F(\circ)=\sigma_{0} z+\sigma_{1} \frac{d z}{d t}+\sigma_{2} v
$$

where $\sigma_{0}$ is the stiffness, $\sigma_{1}$ is the damping coefficient that stands for the dissipation energy due to the deflection of bristles and $\sigma_{2}$ is viscous coefficient. The parametric equation of function $g(v)$ that can describe Stribeck effect is given by

$$
\sigma_{0} g(v)=F_{C}+\left(F_{S}-F_{C}\right) e^{-(v / v)^{2}}
$$

where $F_{C}$ is Coulomb friction force (torque), $F_{S}$ is maximum amount of presliding friction force (torque) and $v_{s}$ is the Stribeck velocity. The proposed model can be characterized by six parameters which are $\sigma_{0}, \sigma_{1}, \sigma_{2}, F_{C}, F_{S}$ and $v_{s}$. This model can simulate most of the behaviors that are observed by friction in practice. These behaviors are not only attributed to the value of parameters but also are affected by nonlinear differential equation (1). Presliding displacement and variable break-away force are due to the system dynamics. The Stribeck shape of function $g(v)$ and model dynamics lead to hysteresis (Canudas et al., 1995).

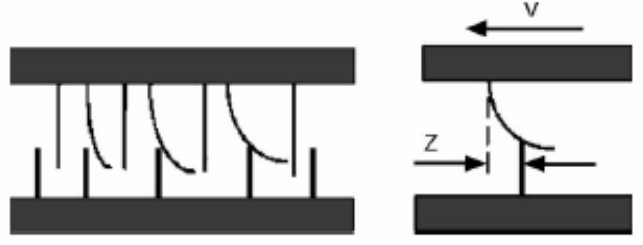

Fig. 5. Friction model

\section{Positioning system modelling}

Schematic diagram of a ball screw driven stage is illustrated in Fig.6. Rotational dynamics of the system can be described as follows:

$$
\left(J_{r o t}+m^{*} l_{p}^{2}\right) \frac{\ddot{x}_{1}}{l_{p}}+F(\circ)=u(t)
$$

where $J_{r o t}$ is the total rotational inertia of ball screw and motor, $m$ is the moving masses, $l_{p}$ is the lead pitch of the ball screw, $F(\circ)$ is the equivalent frictional torque of the ball screw, 
rotary and linear bearings and $u(t)$ is the input torque that is generated by a servo motor. The term $\frac{\ddot{x}_{1}}{l_{p}}$ is equivalent to ball screw rotational acceleration and also the term $m^{*} l_{p}^{2}$ stands for rotational inertia of moving masses. Equation (4) can be simplified since the frictional torque of the ball screw dominates the system. In designing the controllers, the reduced form of equation (4) will be used.

$$
J \ddot{\theta}+F(\circ)=u(t)
$$

where $J$ is the effective inertia of ball screw, motor and equivalent rotational inertia of moving masses. The significant parameters of the system are listed in Table 1.

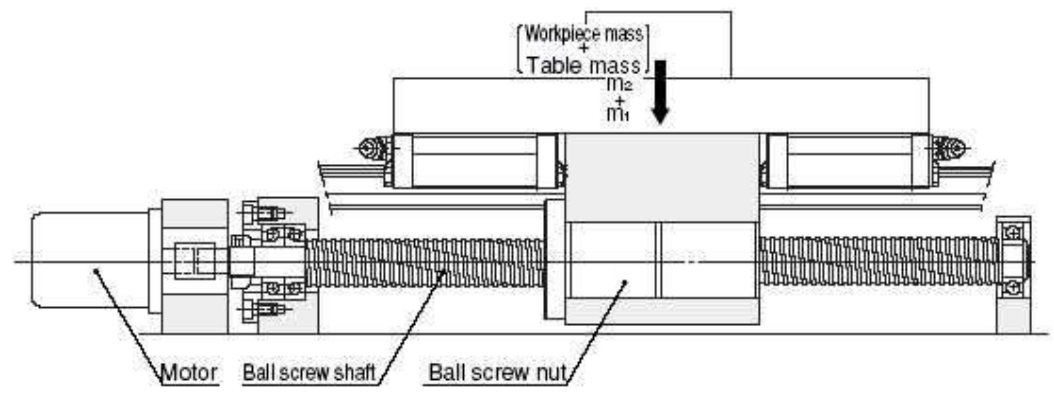

Fig. 6. Schematic of a ball screw driven stage

\begin{tabular}{|c|c|}
\hline $\begin{array}{c}\text { Moment of inertia of ball } \\
\text { screw and motor }\end{array}$ & $2.12^{*} 10^{-4}\left(\mathrm{Kg} \cdot \mathrm{m}^{2}\right)$ \\
\hline $\begin{array}{c}\text { Maximum mass of table } \\
\text { and work }\end{array}$ & $62.4(\mathrm{Kg})$ \\
\hline Lead pitch & $1.5923(\mathrm{~mm} / \mathrm{Rad})$ \\
\hline
\end{tabular}

Table 1. System parameters

\section{Control design}

\subsection{Uncertainties and control approaches}

From engineering control viewpoint the inaccuracy of implemented model for a dynamic system can be categorized into these two comprehensive groups:

- Parameter uncertainties: the uncertainty or variation of the governing parameters of the dynamic model of the system.

- Unstructured uncertainties or unmodeled dynamics: This originates from the undetermined dynamic model of the system.

The existence of model inaccuracy can have strong adverse effect on nonlinear control systems. To safeguard the system from these harmful effects, adaptive and robust control techniques are widely used. If the system is suffering from parameter uncertainties it is possible to apply online or off-line parameter estimation techniques. As instance, adaptive control schemes can be regarded as a control system with on-line parameter estimation. But 
existence of unknown and time varying effective parameters and lack of sufficient information from dynamic behavior of the system, limit the application of adaptive methods.

Variety of control approaches are devised to deal with the effect of unmodeled dynamics which one simple and important of them is sliding mode control. Because of the robustness, the sliding mode control is known as an effective control scheme of the systems with unstructured uncertainties. The only shortcoming of sliding mode controller is its vulnerability to chattering effect. However several compensating techniques are devised to increase the precision of tracking and also to decrease chattering effect. As instance, integral sliding mode controller, time varying boundary layer sliding mode controller and the combination of sliding controller and fuzzy controllers could be mentioned. As seen above, dynamic equation of the ball screw driven stage has frictional term and since there is no exact model for friction and friction model parameters are not known exactly and may be changed, it seems that sliding mode control could be a suitable control scheme for overcoming the adverse effect of these uncertainties. Sliding mode control is described in following subsections.

\subsection{Sliding mode control}

Considering the nth-order SISO nonlinear system described by

$$
y^{(n)}=f\left(y, \dot{y}, \ldots, y^{(n-1)}, t\right)+u
$$

Assume that $f$ is not known precisely but can be written as $f=\hat{f}+\Delta f$, where $\hat{f}$ is the nominal term and $\hat{f}$ is the uncertain term that is bounded by known function $\tilde{F}$, i.e.,

$$
|\Delta f(\mathrm{x}, t)| \leq \tilde{F}(\mathrm{x}, t)
$$

where $\mathrm{x}=\left[x_{1}, x_{2}, \ldots, x_{n}\right]^{T}=\left[y, \dot{y}, \ldots, y^{(n-1)}\right]^{T}$. The control objective is to find a continuous sliding control $u$ such that the output $y$ of (6) will approximately track a reference signal, $y_{r}$, which is assumed to be nth-order continuously differentiable and all of its derivatives are uniformly bounded. The tracking error is given by:

$$
e(t)=y(t)-y_{r}(t)
$$

By defining the generalized error

$$
s=\left(\frac{d}{d t}+\lambda\right)^{n} \xi
$$

where $\xi=\int^{t} e(\tau) d \tau$ and $\lambda>0$, nth-order tracking problem is converted to 1st-order stabilization problem in variable s. $s$ is equivalent to time variable surface in system state space $R^{n}$ defined by $s(x, t)=0$ It is easy to show that by using the control input

$$
u=\hat{u}+v_{c}
$$

where

$$
\hat{u}=-\hat{f}+x_{d}^{(n)}-\sum_{k=0}^{n-1}\left(\begin{array}{c}
n+1 \\
k+1
\end{array}\right) e^{(k)} \lambda^{n-k}-\lambda^{n+1} \xi
$$


and

$$
v_{c}=-K * \operatorname{sat}\left(\frac{s}{\phi}\right)
$$

where $\phi$ is boundary layer thickness, $K=\tilde{F}(x, t)+\eta$ and $\eta$ is the positive constant, the reaching condition (12) in the feedback control system can be satisfied.

$$
\frac{1}{2} \frac{d}{d t} s^{2} \leq-\eta|s| \quad \forall|s| \geq \phi
$$

This equation indicates that the squared distance to surface $s$, that measured by $s^{2}$, decreases along all system trajectories. $s(t)$ verifying (12) is known as a sliding surface and the system's behavior once on the surface is called sliding mode. Despite the presence of model imprecision and disturbance, $s^{2}$ remains a Lyapunov - like function of closed loop system. In addition, this control input ensures that starting from any initial state, the error trajectories will be in boundary layer $|s| \leq \phi$ after finite time. Whenever $|s| \leq \phi$, the guaranteed tracking precision will be

$$
\left|e^{(i)}\right| \leq(2 \lambda)^{i} \varepsilon
$$

where $\varepsilon=\phi / \lambda^{n-1}$ is known as boundary layer width and is shown in Fig. 7 for the case $n=2$ (Slotine \& Li, 1991).

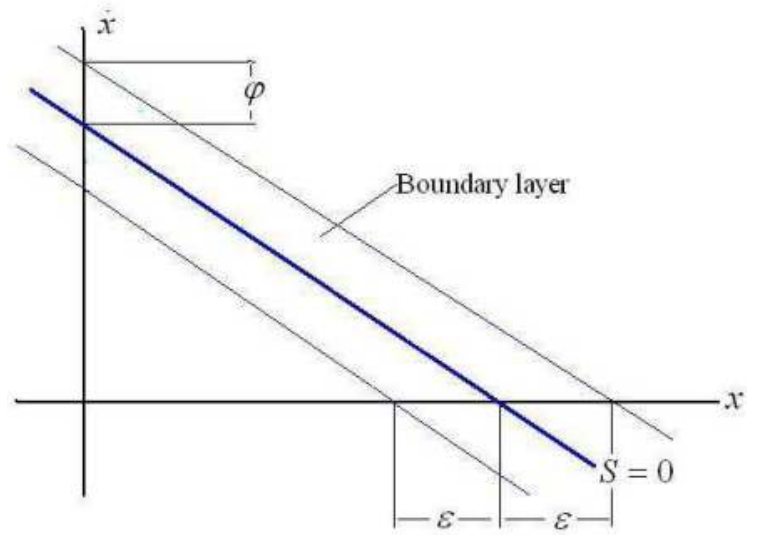

Fig. 7. The boundary layer for the case $n=2$

\subsection{Complementary sliding mode control}

Now an additional complementary transformation to the generalized error is defined as

$$
s_{c}=\left(\frac{d}{d t}+\lambda\right)^{n-1}\left(\frac{d}{d t}-\lambda\right) \xi
$$

The control input is given by (9) with $\hat{u}$ is defined in (10) and $v_{c}$ is replaced by 


$$
v_{c}=-K * \operatorname{sat}\left(\frac{s+s_{c}}{\phi}\right)
$$

By applying this control input to the system, any initial state off the boundary layer will move to the boundary layer $\left|s+s_{c}\right| \leq \phi$ in finite time and tracking precision will be

$$
\left|e^{(i)}\right| \leq \frac{1}{2}(2 \lambda)^{i} \varepsilon
$$

whenever the system state will be in boundary layer. It is obvious that the tracking precision is at least $50 \%$ better than that of in conventional sliding mode control (Liang \&, 2003).

\subsection{Fuzzy sliding mode control}

Based on the definitions of generalized errors, a fuzzy sliding mode controller can be constructed. The fuzzy control input is in the form of

$$
u=\hat{u}+K_{f}\left(s, s_{c}\right)
$$

where $\hat{u}$ is given in (10) and $K_{f}\left(s, s_{c}\right)$ is the output of fuzzy controller. The fuzzy rules are in the form of:

$$
\text { Rule }^{i} \text { :if } s=L S^{i} \text { and } s_{c}=L S_{c}^{i} \text {, then } u=L U^{i}
$$

where $L S^{i}$ and $L S_{c}^{i}$ are the linguistic values of $s$ and $s_{c}$, respectively. By appropriate tuning the parameters of fuzzy controller, a high performance controller can be obtained and no further information about uncertainties of the system will be needed. It is worth to point out that because the fuzzy controller is constructed on sliding mode controller which is robust, the stability of fuzzy controller would be guaranteed (Liang \&, 2003).

\section{Parameter design}

The constant characteristic parameters of friction model in the ball screw driven stage, i.e. $\sigma_{0}, \sigma_{1}, \sigma_{2}, F_{C}, F_{S}$ and $v_{s}$, parameters for evaluating $\hat{f}$ (i.e. $\hat{\sigma}_{0}, \hat{\sigma}_{1}, \hat{\sigma}_{2}, \hat{F}_{C}, \hat{F}_{S}$ and $\hat{v}_{s}$ ) and parameters for evaluating $\tilde{F}$ (i.e. $\tilde{\sigma}_{0}, \tilde{\sigma}_{1}, \tilde{\sigma}_{2}, \hat{F}_{C}, \hat{F}_{S}$ and $\hat{v}_{s}$ ) are listed in table 2 . The parameters $\sigma_{0}, \sigma_{1}, \sigma_{2}$, and $v_{s}$ are the same as reference (Canudas et al., 1995) while $F_{\mathrm{C}}$ and $F_{S}$ are selected arbitrarily. The values of parameters of $\hat{f}$ are assumed to be uncertain enough in order to enable us validate our claims about robustness of the controllers.

\begin{tabular}{|c|c|c|c|c|c|c|}
\hline$\sigma_{0}$ & $10^{5}$ & $\hat{\sigma}_{0}$ & $2 * 10^{5}$ & $\tilde{\sigma}_{0}$ & $10^{5}$ & $\mathrm{Nm} / \mathrm{Rad}$ \\
\hline$\sigma_{1}$ & $\sqrt{10^{5}}$ & $\hat{\sigma}_{1}$ & $2 * \sqrt{10^{5}}$ & $\tilde{\sigma}_{1}$ & $\sqrt{10^{5}}$ & $\mathrm{Nms} / \mathrm{Rad}$ \\
\hline$\sigma_{2}$ & 0.4 & $\hat{\sigma}_{2}$ & 1.2 & $\tilde{\sigma}_{2}$ & 1 & $\mathrm{Nms} / \mathrm{Rad}$ \\
\hline$F_{C}$ & 6.24 & $\hat{F}_{C}$ & 6.24 & $\hat{F}_{C}$ & 6.24 & $\mathrm{Nm}$ \\
\hline$F_{S}$ & 9.36 & $\hat{F}_{S}$ & 9.36 & $\hat{F}_{S}$ & 9.36 & $\mathrm{Nm}$ \\
\hline$v_{s}$ & 0.001 & $\hat{v}_{s}$ & 0.005 & $\hat{v}_{s}$ & 0.005 & $\mathrm{Rad} / \mathrm{s}$ \\
\hline
\end{tabular}

Table 2. Parameters of friction model 


\section{Computer simulation and analysis}

In order to evaluate the performance of the proposed controllers in control of ball screw positioning system some simulations are performed in Matlab/ Simulink and Matlab/ Fuzzy toolbox and tracking error and control input to the system are compared when the system tracks various desired signals. We take $\lambda=150, \eta=120$ and $\phi=0.1$ in simulation of the system when conventional sliding mode controller is applied. In simulation of the system when complementary sliding mode controller is applied, the constants parameters are taken as $\lambda=150, \eta=20$ and $\phi=0.1$. $\lambda$ equals to 150 in simulation of the system with fuzzy sliding mode controller. The membership functions of input variables $s$ and $s_{\mathcal{c}}$ to the fuzzy controller are shown in Fig. 8. Membership functions of output variable $K_{f}\left(s, s_{c}\right)$ of the fuzzy controller are shown in Fig. 9. We used Mamdani method for fuzzy inference system, fuzzifier type was triangular and defuzzifier type was centroid.

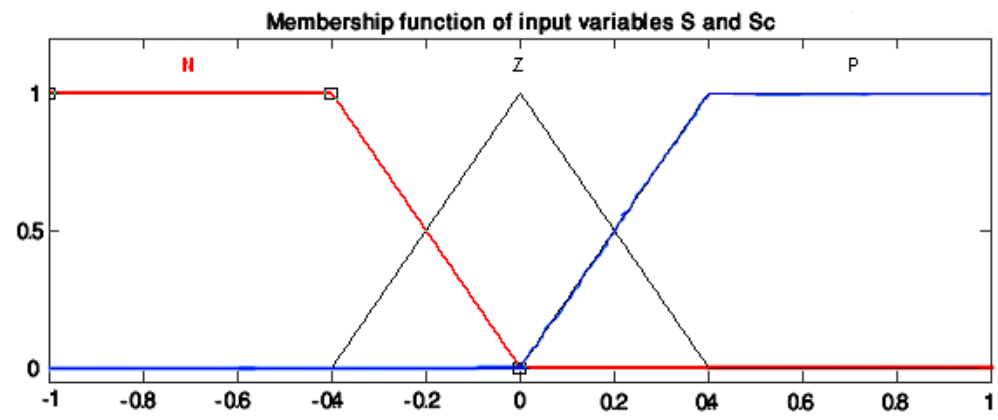

Fig. 8. Membership functions of input variables $s$ and $s_{c}$

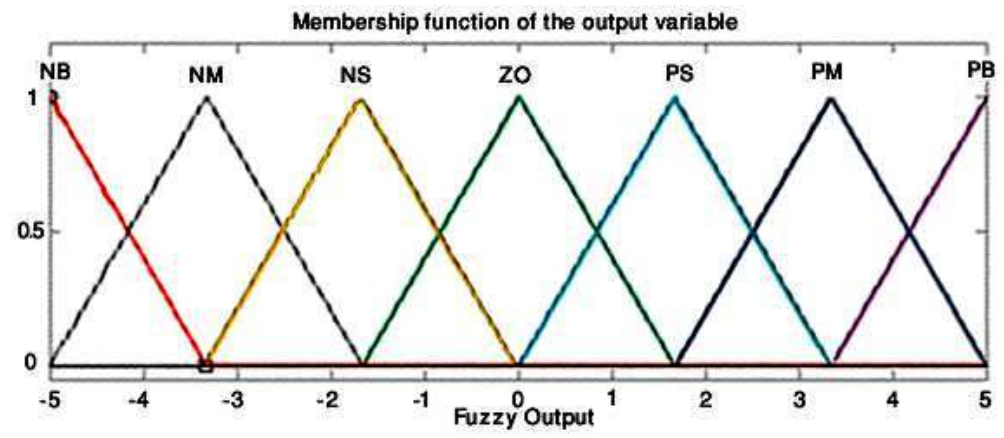

Fig. 9. Membership functions of output variable of the fuzzy controller

We develop the rule base of the fuzzy controller which $s$ and $s_{c}$ are its input variables and is the output variable in the form of

1. If " $s$ " is " $\mathrm{N}$ " and " $s_{\mathcal{C}}$ " is " $\mathrm{P}$ " then "Fuzzy Output" is "PB".

2. If " $s$ " is " $N$ " and " $s_{c}$ " is " $Z$ " then "Fuzzy Output" is "PS". 
3. If " $s$ " is " $N$ " and " $s_{c}$ " is " $N$ " then "Fuzzy Output" is " $Z O$ ".

4. If " $s$ " is " $Z$ " and " $s_{\mathcal{C}}$ " is " $P$ " then "Fuzzy Output" is "PS".

5. If " $s$ " is " $Z$ " and " $s_{c}$ " is " $Z$ " then "Fuzzy Output" is " $Z O$ ".

6. If " $s$ " is " $Z$ " and " $s_{c}$ " is " $N$ " then "Fuzzy Output" is "NS".

7. If " $s$ " is " $\mathrm{P}$ " and " $s_{c}$ " is " $\mathrm{P}$ " then "Fuzzy Output" is " $Z \mathrm{O}^{\prime}$ ".

8. If " $s$ " is " $P$ " and " $s_{C}$ " is " $Z$ " then "Fuzzy Output" is "NS".

9. If " $s$ " is " $\mathrm{P}$ " and " $s_{\mathcal{C}}$ " is " $\mathrm{N}$ " then "Fuzzy Output" is "NB".

where $\mathrm{P}$ stands for positive; $\mathrm{N}$ stands for negative; $\mathrm{PB}$ stands for positive big; PS stands for positive small; both Z and ZO stand for zero; NB stands for negative big, and NS stands for negative small. The scaling factors of input and output variables are shown in Fig. 10.

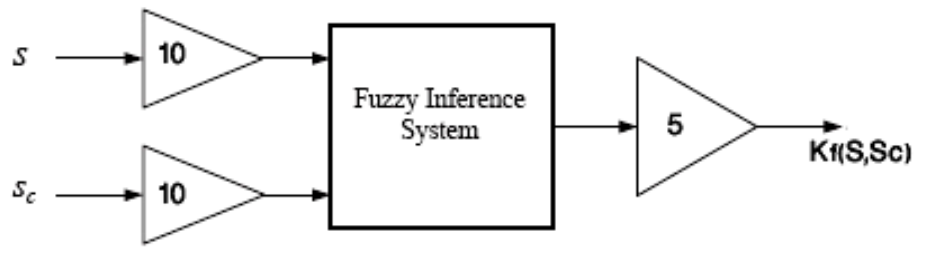

Fig. 10. Scaling factor of input and output variables of fuzzy controller

The response of the proposed controllers to positioning signal $1(\mathrm{~mm})$ is shown in Fig. 11. As seen in this figure, SMC has the maximum positioning error and FSMC has the minimum one. Also steady state error exists in the response of the SMC to this signal, but CSMC and FSMC are capable of eliminating this error in their responses. The control inputs of the SMC and CSMC are not zero after reaching the desired positions that can be attributed to spring like behavior of friction. But FSMC is capable of setting the control input to zero. But since the gains of fuzzy controller are not suitable for very small amount of error, an oscillating behavior is observed in control input.

The responses of the proposed controllers for various sinusoidal inputs with different amplitudes and frequencies are shown in Fig. 12 to Fig. 14. The results indicate that tracking error exists when SMC is applied to the system dynamics and control input to the system undergoes to fluctuations and high frequency chatter in some cases. Also this controller can not response properly to high frequency reference signal and its performance suffers from large tracking error, fluctuations and oscillations in control input. When CSMC is applied to the system, the tracking error becomes smaller in comparison with SMC. Its peaks occurred in the points where the direction of the motion is changed. Fluctuations and chatters in control inputs are also observed in this case but frequency of chattering is lower. High frequency reference signal can not be tracked properly in this case because of large tracking error and large values of fluctuations in the control input. FSMC is capable of eliminating tracking error except for where the direction of motion is changed and the occurred error is damped in finite time (less than 0.1 (s)). Control inputs are more smooth in this case and do not include fluctuations and chattering. The response of the controller is more desirable to high frequency reference signal. Tracking error does not grow drastically in this case and control input does not suffer from fluctuations and oscillations. 


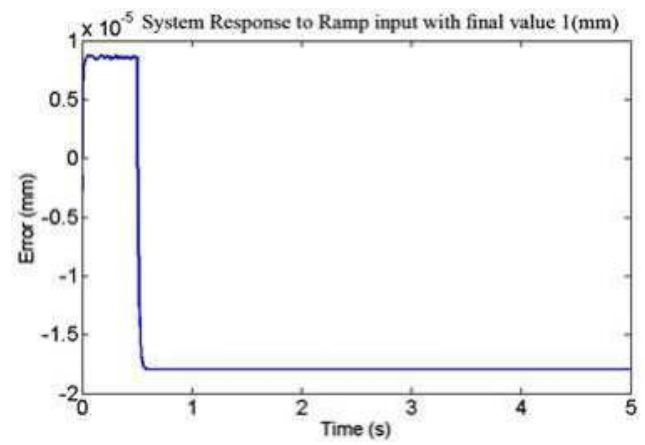

(a)

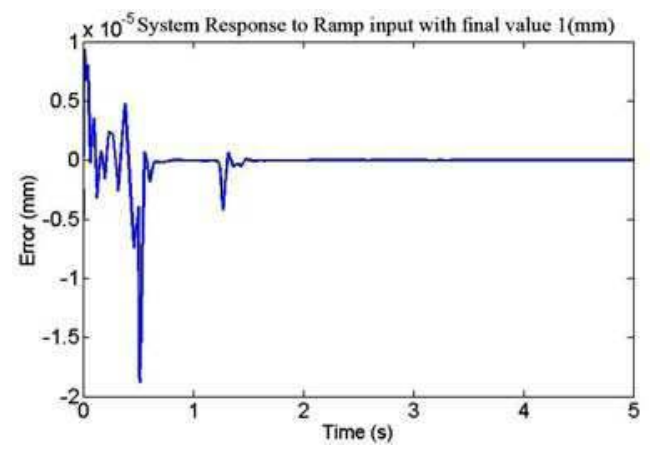

(c)

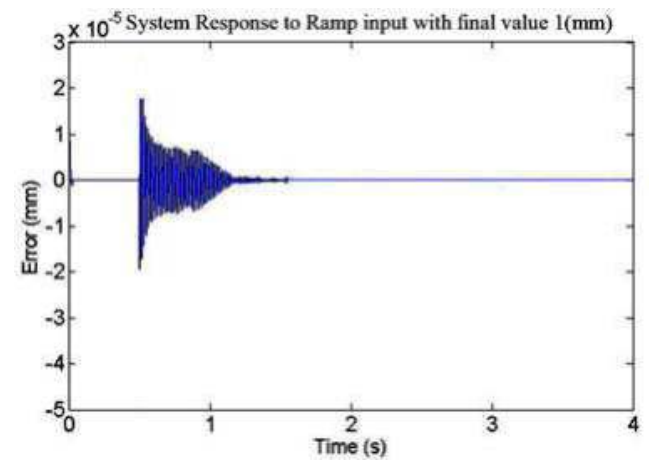

(e)

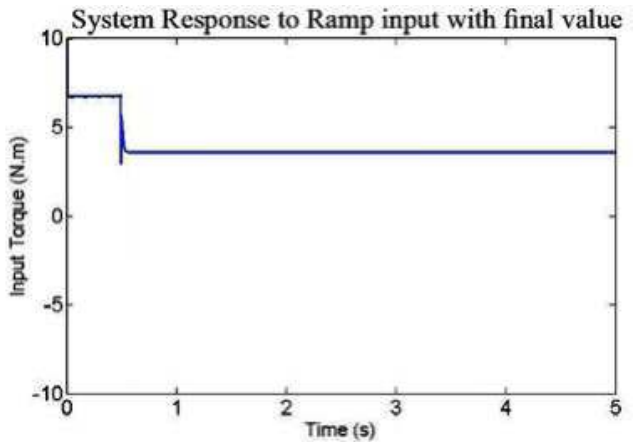

(b)

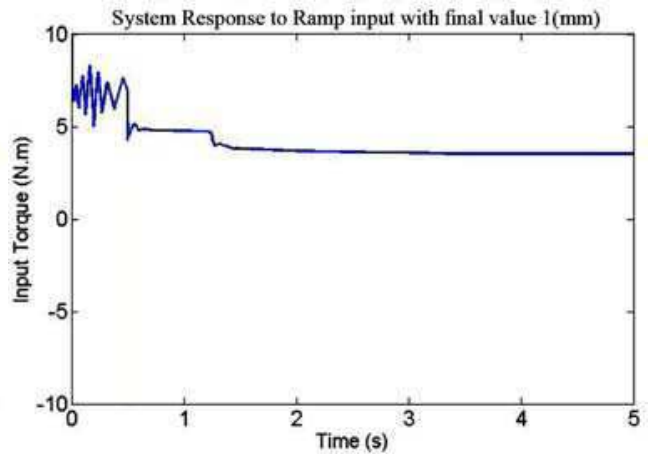

(d)

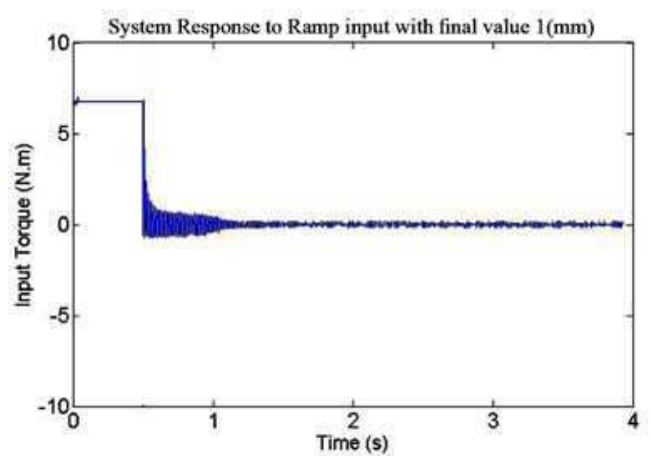

(f)

Fig. 11. Positioning response to step input with final value $1(\mathrm{~mm})$. (a) Positioning error of SMC, (b) Control input of SMC, (c) positioning error of CSMC, (d) Control input of CSMC, (e) positioning error of FSMC, (f) Control input of FSMC. 


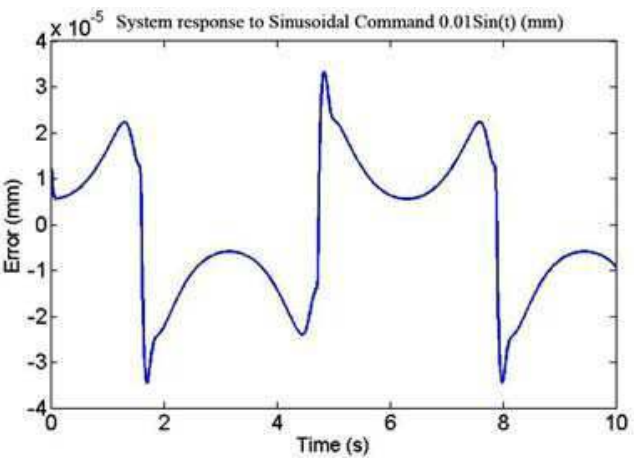

(a)

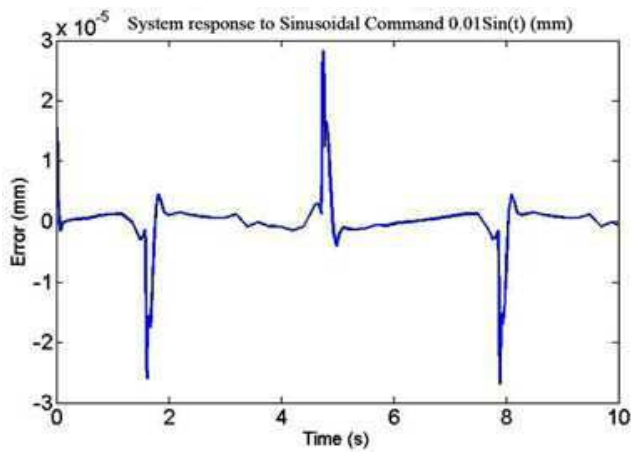

(c)

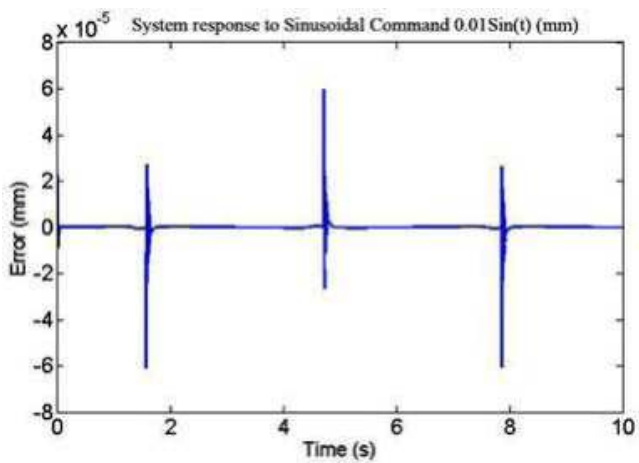

(e)

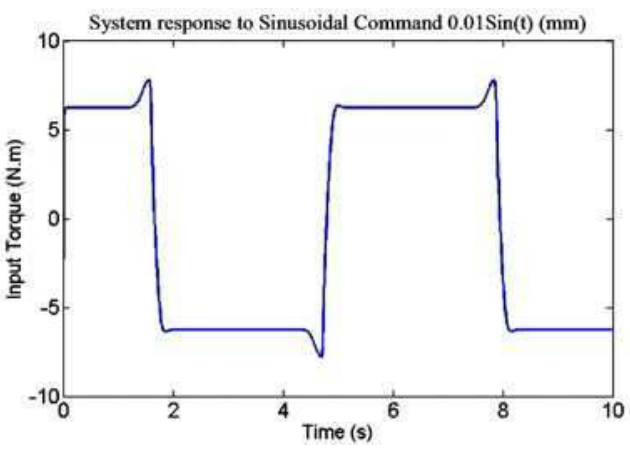

(b)

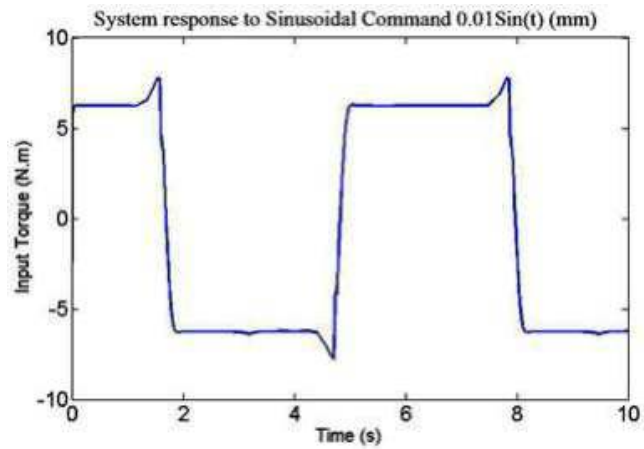

(d)

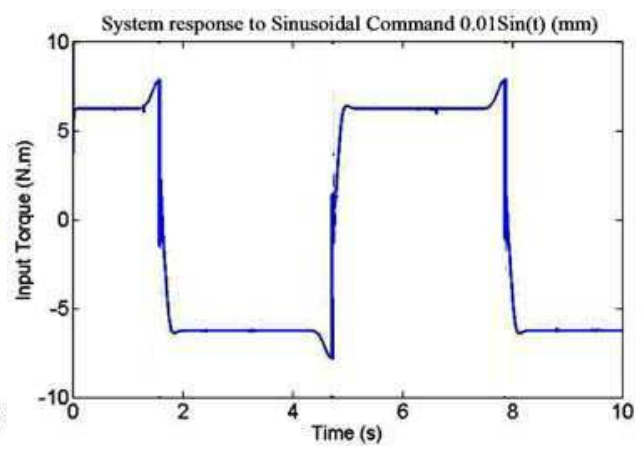

(f)

Fig. 12. Tracking response to sinusoidal input 0.01Sin(t) (mm). (a) Tracking error of SMC, (b) Control input of SMC, (c) Tracking error of CSMC, (d) Control input of CSMC, (e) Tracking error of FSMC, (f) Control input of FSMC 


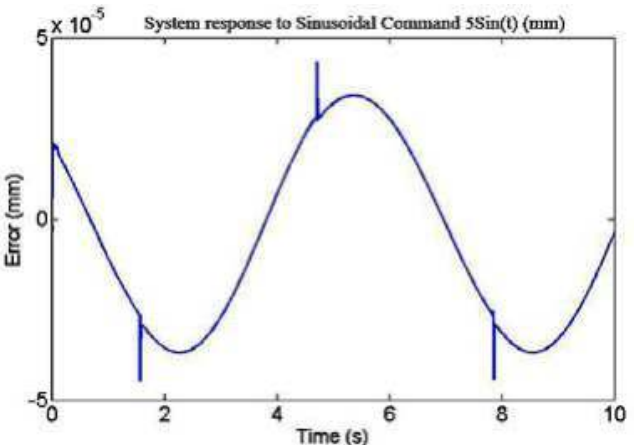

(a)

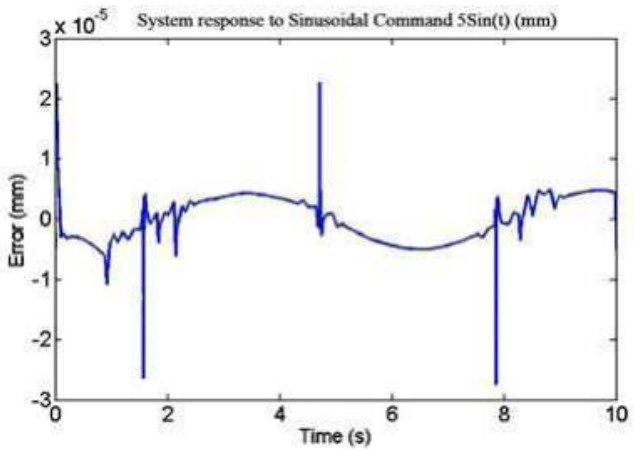

(c)

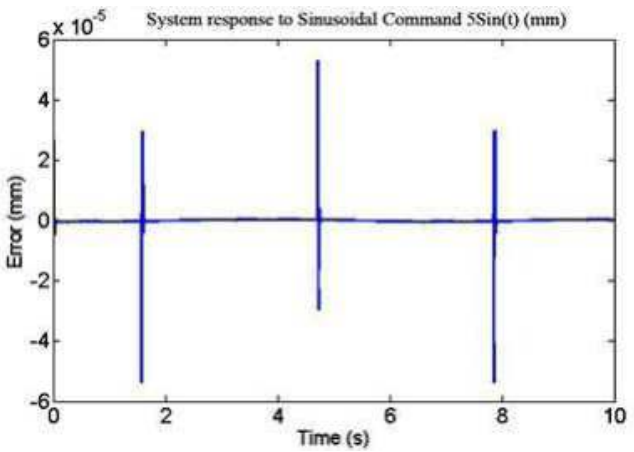

(e)

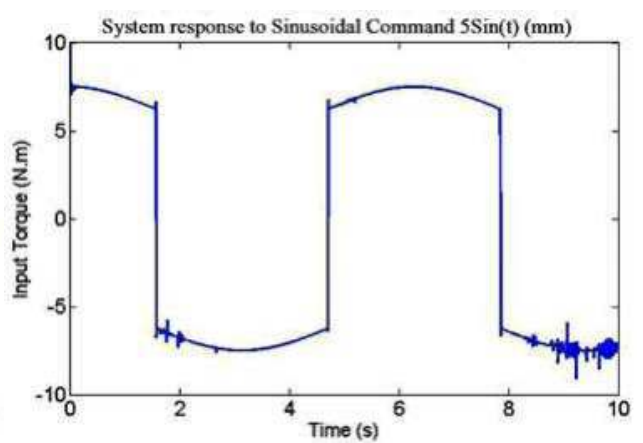

(b)

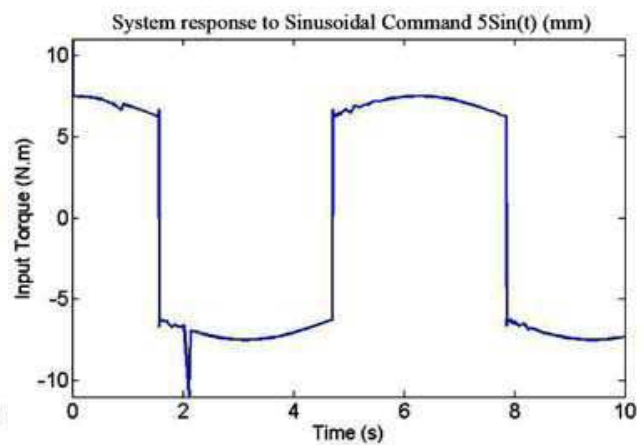

(d)

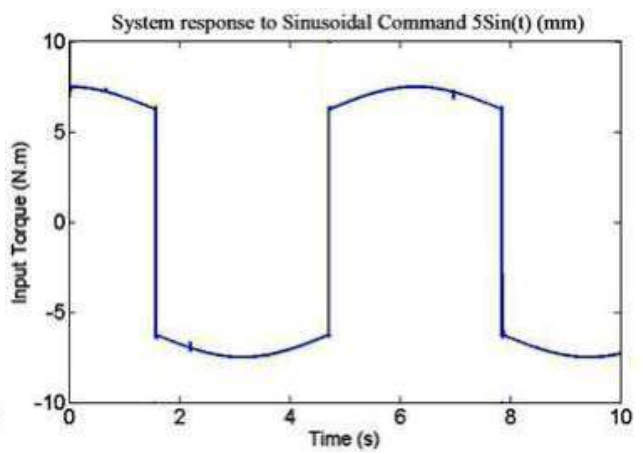

(f)

Fig. 13. Tracking response to sinusoidal input $5 \operatorname{Sin}(\mathrm{t})(\mathrm{mm})$. (a) Tracking error of SMC, (b) Control input of SMC, (c) Tracking error of CSMC, (d) Control input of CSMC, (e) Tracking error of FSMC, (f) Control input of FSMC 


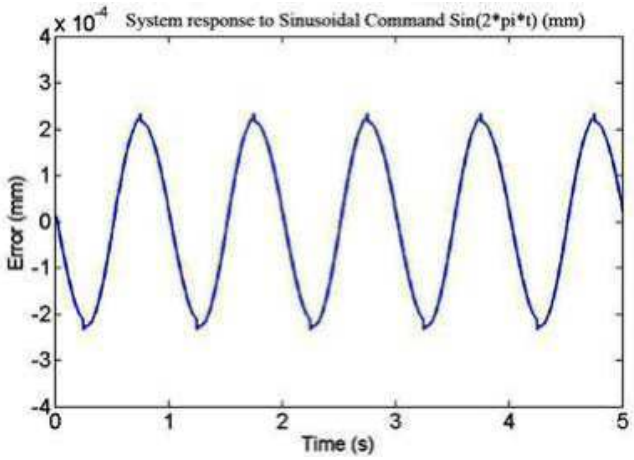

(a)

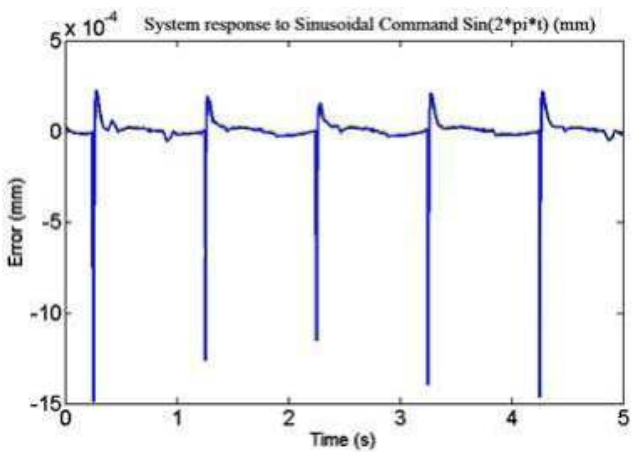

(c)

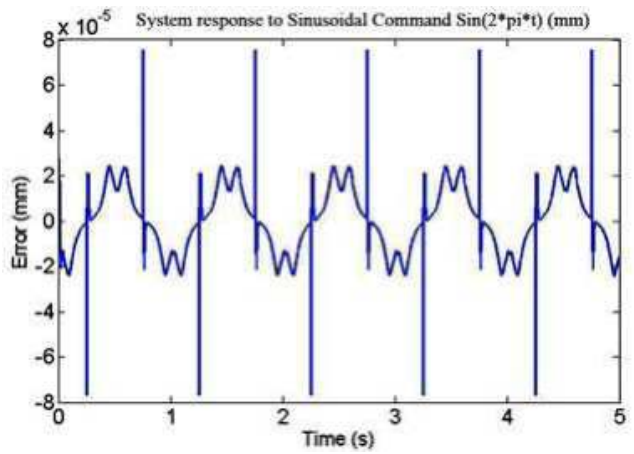

(e)

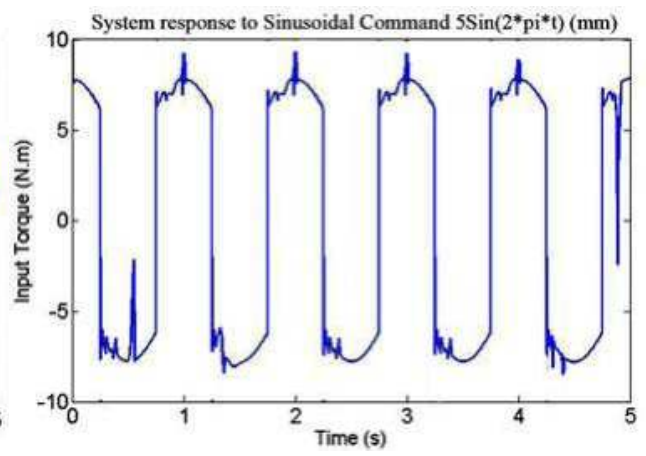

(b)

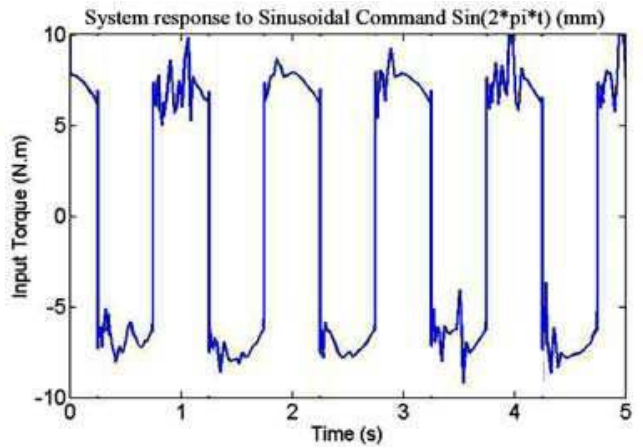

(d)

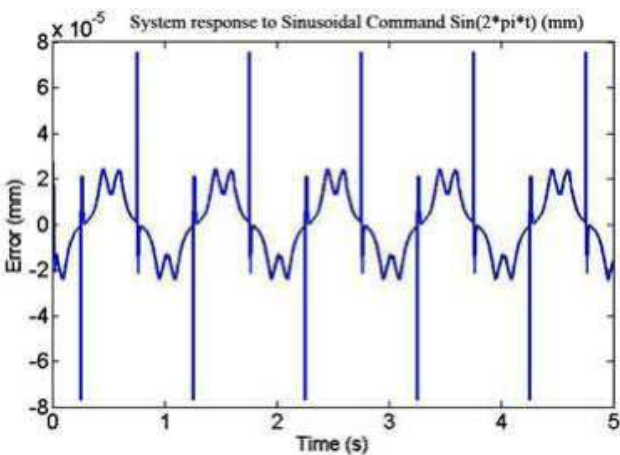

(f)

Fig. 14. Tracking response to sinusoidal input $\operatorname{Sin}\left(2^{*} \mathrm{pi}^{*} \mathrm{t}\right)(\mathrm{mm})$. (a) Tracking error of SMC, (b) Control input of SMC, (c) Tracking error of CSMC, (d) Control input of CSMC, (e) Tracking error of FSMC, (f) Control input of FSMC 


\section{Verification}

\subsection{Introducing Double Ball Bar (DBB)}

DBB is consisting from two precise balls that each ball is $25.4 \mathrm{~mm}$ in diameter with geometric spherical error of less than $0.05 \mu \mathrm{m}$. These two balls are connected together by a low thermal expansion coefficient bar made of Invar. This bar is equipped with a measurement system with $0.1 \mu \mathrm{m}$ resolution (Fig 15). Each ball magnetically attracted by the support and it is in contact with supporting surface in three points. One of these supports is attached to the machine table and the other one is fastened to the machine spindle. Once DBB assembled correctly, the machine is commanded to move in a circular path. The variations in the distance between the centers of the two balls is measured via the measurement system and corresponding analog signal is converted to digital signal and then its corresponding numerical value is calculated by computer. The variations of mentioned distance is identical to deviation from ideal circular path (Fig 16). Usually the data acquisition rate is such that the computer detects motion error $\Delta R$ in every 0.2 degree. So in every full rotation 1800 numeric values is sampled.

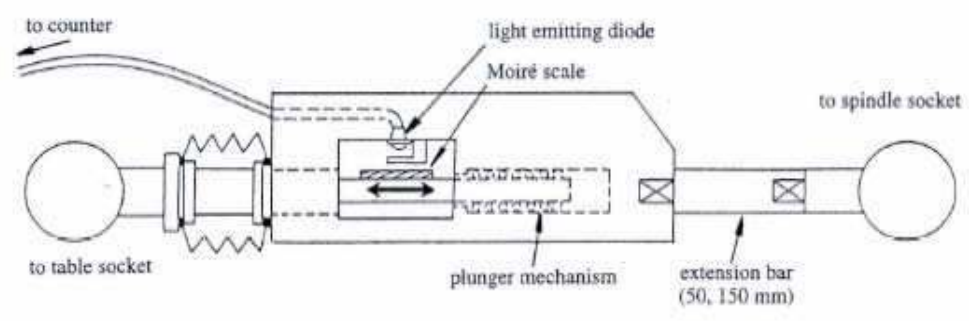

Fig. 15. Schematic of Double Ball Bar. (Kakino et al., 1993)

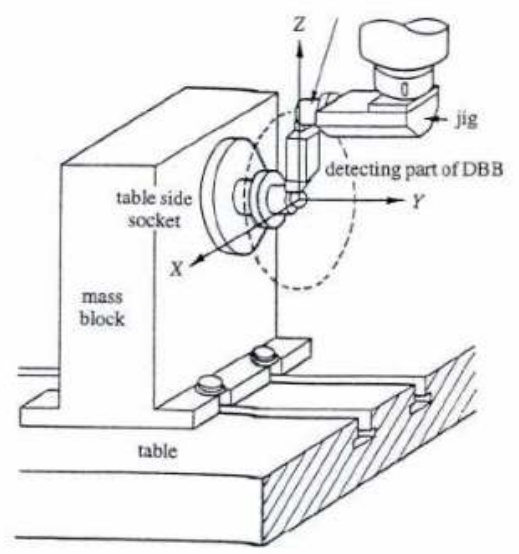

Fig. 16. Setup for accuracy inspection of a machine tool in vertical plane by Double Ball Bar. (Kakino et al., 1993)

\subsection{Errors in CNC machines}

In accuracy inspection of a machine tool by means of $\mathrm{DBB}$, the source of the error in each $\mathrm{CNC}$ machine is divided into two main categories. 
- Errors of which the magnitude is dependent to the feedrate and direction of the motion e.g. errors originated from stick motion, stick-slip behavior and vibration in the hydraulic valves and chains.

- $\quad$ Errors of which the magnitude is dependent to the position e.g. cyclic error of the ball screw and linear encoder, squareness errors between two axes and straightness errors of guide ways.

Most of the errors mentioned above are only practically observable but the effect of stick motion and stick-slip can also be shown in simulations. In the following paragraphs these error will be introduced.

- Stick motion error: This error is originated from lag in the response of control system when the direction of motion is reversed. During reversing the direction of motion, the velocity of the axis decreases to zero and hence static friction becomes the dominant frictional force in the system. Since break-away force is greater than dynamic friction force, the slider stays in stick condition and hence the tracking error increases. By increasing the magnitude of tracking error the controller provides relatively larger control input to the actuator to conquer break- away force and the axis again starts to catch up the reference signal. Fig 17 illustrates the slider in the stick condition for a short time after the direction of motion is reversed. The effect of this error is shown in Fig 18 in a polar coordinate system and with proper magnification. The magnitude of this error is dependent upon the feedrate and the amplitude of the reference signal. As can be seen in the figures 12$14(\mathrm{a}, \mathrm{c}, \mathrm{e})$ the presence of a peak in diagrams of tracking error of sinusoidal reference signal can be attributed to stick motion error.

In the standard ISO 230-4 that is related to the testing of the NC and CNC machines using DBB, it is mentioned that in a machine equipped with linear encoder, reversal error will be detected and compensated by the machine controller but the compensation needs a certain amount of time and therefore some peaks will outbreak in the reversal points. (Figure 19). (BS ISO 230-4, 1996)

- Stick-slip: This phenomenon occurs in very low feedrate and is happening in a continuous sequence of stop and move motion in a short period of time. In a circular motion this phenomenon is observable in zero, 90, 180 and 270 degrees which feedrate of one axis reduces to zero. In Fig 20 illustrate the trace pattern

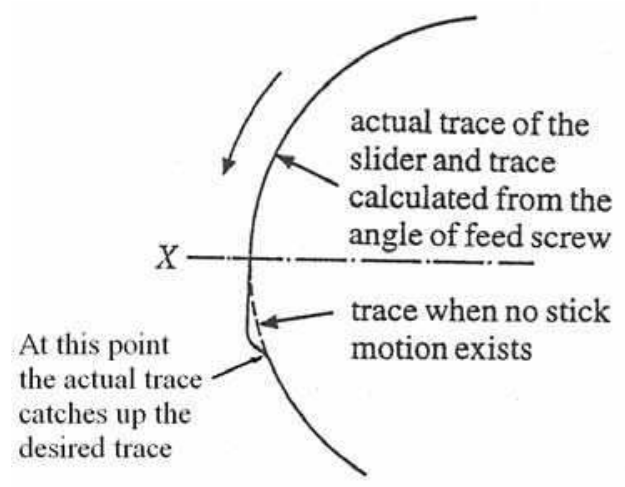

Fig. 17. Model of stick motion. (Kakino et al., 1993) 


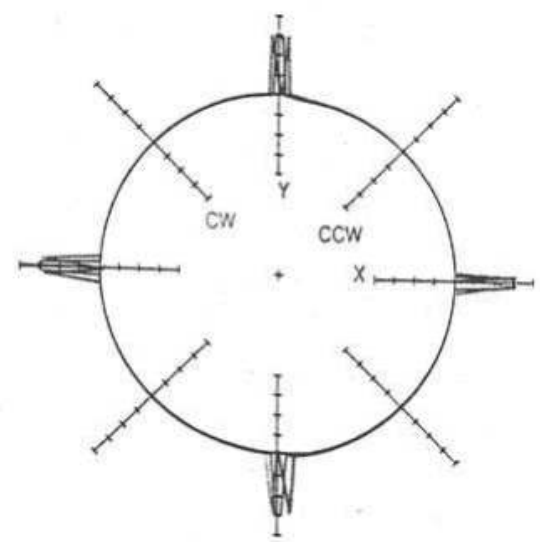

Fig. 18. Trace pattern caused by stick motion. (Kakino et al., 1993)

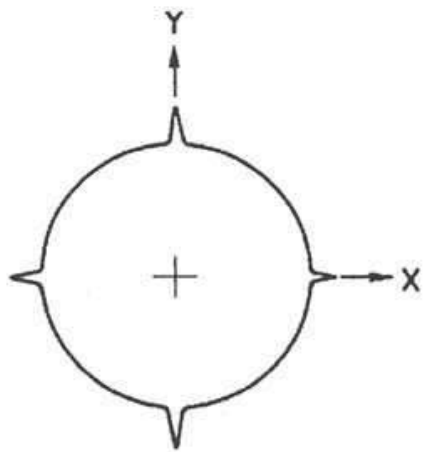

Fig. 19. Compensated reversal error. (BS ISO 230-4, 1996)

caused by stick-slip on a circular motion. It can be seen that there is a symmetric pattern around the axis which has this error. By increasing feedrate, this event decreases and then completely eliminated (Kakino et al., 1993). Since this phenomenon is considered in the assumed frictional model, its effect can not be seen in the simulations.

- In standard ISO 230-4 is mentioned that by increasing feedrate in circular motion the acceleration of the axis increases accordingly and the controller acts in such a way that the amplitude of the movement decreases at higher frequencies (Fig 21) (BS ISO 230-4, 1996). It is also obvious that a circular motion can be produced by combining two ball screw driven stages. The effect of increasing the frequencies of sinusoidal reference signals to each stage is that the diameter of resultant circular path becomes smaller than desired path. This observation also confirms the increase in the magnitude of error which can be seen in figure $14(\mathrm{a}, \mathrm{c}, \mathrm{e})$. These figures are related to sine input to the system with $1 \mathrm{~mm}$ amplitude and 1 second period. Hereby the magnitude of error increases as the frequency of the sine input increases and the magnitude of the error will be such that the amplitude of the resultant motion will be less than the desired value. 


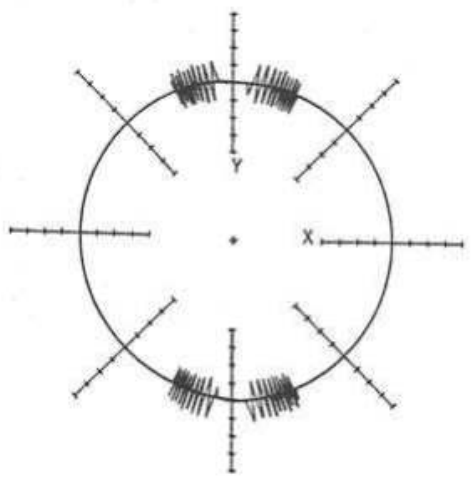

Fig. 20. Trace pattern caused by stick slip. (Kakino et al., 1993)

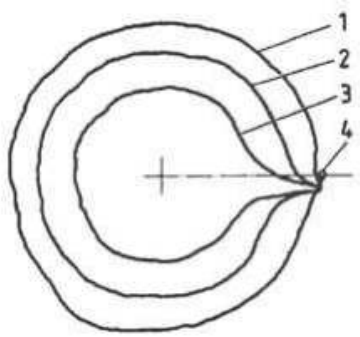

Fig. 21. Influence of acceleration of the axis on amplitude of resultant motion (1- Low feedrate. 2- Medium feedrate. 3- High feedrate. 4- Starting and stop point). (BS ISO 230-4, 1996)

\section{Conclusion}

In recent years, due to the developments in nanotechnology, the demand for high-precision stages has been subjected to great attention. Systems to provide long-range and highprecision performance for positioning, tracking and contouring tasks have become stringent issues. Such systems are widely used in semiconductors, precision metrology, microassembly and micro- and nanoscale fabrication industries. Among the positioning systems, the ball screw driven systems have been widely used in academic researches and in the inferred industries. Several researches have been performed on precise positioning such as modeling friction, implementing different control strategies for compensating friction and achieving micron accuracy. In this chapter, the process of controlling of a single axis ball screw driven stage with micron positioning accuracy has been investigated.

In the first step, two nonlinear phenomena i.e. friction and backlash that can affect the accuracy of the designed stage are studied. Among them, friction has been the most dominant phenomena which significantly reduce the final achievable accuracy. In order to compensate the undesired effects of friction, it is necessary to provide its behavioral model. Among proposed models, Canudas model was selected that can explain frictional behavior of such positioning systems comprehensively and effectively. 
In the next step, the theoretical description of a control system capable of compensating the undesired effects of friction is introduced. Since governing parameters of frictional model are not known accurately, the sliding mode control (SMC) technique is selected which is appropriate in the architecture of controllers with uncertainty. Subsequently a new type of sliding mode control approach known as complementary sliding mode (CSMC) and fuzzy sliding mode control (FSMC) was introduced and discussed.

Finally the described controllers are applied to nonlinear dynamics of the system and their performances were investigated by computer simulation for submicrometer positioning, tracking and control input. It is observed that not only FSMC could significantly improve the achievable accuracy of positioning and tracing, but also it is capable of smoothing inputs to the system and eliminating fluctuations. Also this type of controller has better response to high frequency sinusoidal reference signals. Finally the results have been validated by comparing them with those achieved from Double Ball Bar experimental results. Further investigation on evaluating the controllers' performances in the presence of other type of uncertainty such as inertia will be held in future.

\section{References}

Bliman, P.A \& Sorine, M. (1991). Friction modelling by hysteresis operators. Application to Dahl, Stiction, and Stribeck effects, in Proc. Conf. Models of Hysteresis, Trento, Italy.

Canudas de Wit, C.; Olsson, H., Astrom, K.J. \& Lischinsky, P. (1995). A new model for control of systems with friction, IEEE Transaction on Automatic Control, Vol 40, No.3.

Chen, C.L.; Jang, M.J. \& Lin K.C. (2004). Modeling and High Precision Control of a Ballscrew Driven Stage, Precision Engineering, pp. 483-495.

Dahl, P. (1968). A solid friction model, Aerospace Corp., EI Segundo, CA, Tech, Rep. TOR0158(3107-18).

Kakino, Y.; Ihara, Y.; Shinohara, A \& Heidenhain, J. (1993). Accuracy Inspection of NC Machine Tools by Double Ball Bar Method, Hanser Gardner Publications, ISBN: 1569901600, Cincinnati, Ohio.

Liang, C.Y. \& Su, J.P. (2003). A New Approach to the Design of a Fuzzy Sliding Mode Controller, Fuzzy Sets and Systems, pp. 111-124.

Lee, H.; Kim, E.; Kang, H.J. \& Park, M. (2001). A new sliding-mode control with fuzzy boundary layer, Fuzzy Sets and Systems, pp. 135-143.

Marchi, J.A. (1998). Modeling of Dynamic Friction, Impact Backlash and Elastic Compliance Nonlinearities in Machine Tools, With Application to Asymmetric Viscous and Kinetic Friction Identification, A Thesis Submitted to the Graduate Faculty of Rensselaer Polytechnic Institute in Partial Fulfillment of the Requirements for the Degree of Doctor of Philosophy. Rensselaer Polytechnic Institute. Troy, New York.

Slotine, J.E. \& Li. W.P. (1991). Applied Nonlinear Control, Prentice Hall, ISBN: 0130408905.

Mihajlov1, M.; Nikolić, V. \& Antić, D. (2002). Position control of an electro hydraulic servo system using sliding mode control enhanced by fuzzy PI controller, Mechanical Engineering, Vol.1, pp.1217-1230.

Ro, P.I.; Shim, W. \& Jeong, S. (2000). Robust Friction Compensation for Submicrometer Positioning and Tracking for a Ball-Screw-Driven Slide System, Precision Engineering, pp. 160-173

(1996). Test code for machine tools - Part 4: Circular tests for numerically controlled machine tools, BS ISO 230-4, 12 pages. 


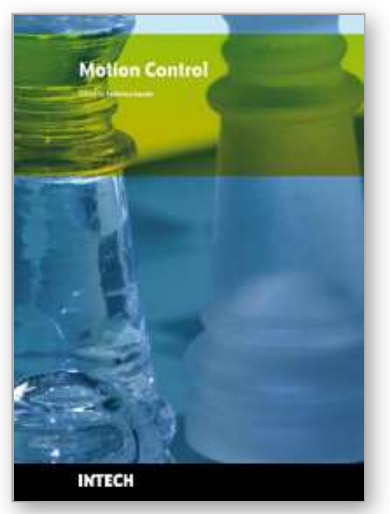

\author{
Motion Control \\ Edited by Federico Casolo
}

ISBN 978-953-7619-55-8

Hard cover, 590 pages

Publisher InTech

Published online 01, January, 2010

Published in print edition January, 2010

The book reveals many different aspects of motion control and a wide multiplicity of approaches to the problem as well. Despite the number of examples, however, this volume is not meant to be exhaustive: it intends to offer some original insights for all researchers who will hopefully make their experience available for a forthcoming publication on the subject.

\title{
How to reference
}

In order to correctly reference this scholarly work, feel free to copy and paste the following:

Mohammad Shams and Masoud Safdari (2010). Fuzzy Sliding Mode Control of a Ball Screw Driven Stage, Motion Control, Federico Casolo (Ed.), ISBN: 978-953-7619-55-8, InTech, Available from:

http://www.intechopen.com/books/motion-control/fuzzy-sliding-mode-control-of-a-ball-screw-driven-stage

\section{INTECH}

open science | open minds

\section{InTech Europe}

University Campus STeP Ri

Slavka Krautzeka 83/A

51000 Rijeka, Croatia

Phone: +385 (51) 770447

Fax: +385 (51) 686166

www.intechopen.com

\section{InTech China}

Unit 405, Office Block, Hotel Equatorial Shanghai

No.65, Yan An Road (West), Shanghai, 200040, China 中国上海市延安西路65号上海国际贵都大饭店办公楼 405 单元

Phone: +86-21-62489820

Fax: +86-21-62489821 
(C) 2010 The Author(s). Licensee IntechOpen. This chapter is distributed under the terms of the Creative Commons Attribution-NonCommercialShareAlike-3.0 License, which permits use, distribution and reproduction for non-commercial purposes, provided the original is properly cited and derivative works building on this content are distributed under the same license. 